\title{
Blockchain technology in energy markets - An interview with the European Energy Exchange
}

\author{
Rainer Alt ${ }^{1}$ (D) Erik Wende ${ }^{2}$ \\ Received: 4 May 2020 / Accepted: 4 May 2020 / Published online: 30 June 2020 \\ (C) The Author(s) 2020
}

\section{Abstract}

What is the impact of blockchain technology on electronic markets in the energy sector? In this interview with Electronic Markets, Dr. Tobias Paulun, chief strategy officer of the European Energy Exchange (EEX), explains where the leading European energy exchange recognizes potentials of blockchain technology compared to existing electronic platforms and which blockchain projects EEX is working on. In his view, the impact of blockchain technology depends on the respective market segment and on the availability of solutions for safeguarding guarantees of origin. He expects that established exchange systems and blockchain-based systems will coexist in this strongly regulated and specialized industry.

\section{Personal details}

Tobias Paulun studied electrical engineering with a focus on energy technology at RWTH Aachen in Germany. After completing his Ph.D. in engineering, he finished a second doctoral degree in economics and was involved in several industrial studies and research projects, in particular in the field of grid planning for power and gas transmission system operators. In summer 2009, he joined EEX Group, where he is now responsible for the strategy department and has been on the Management Board since 2015. This includes, in particular, product development and corporate strategy aspects (such as cooperations and mergers), as well as political and regulatory communication.

Keywords Energy exchange $\cdot$ Power exchange $\cdot$ Decentralized markets $\cdot$ Blockchain technology
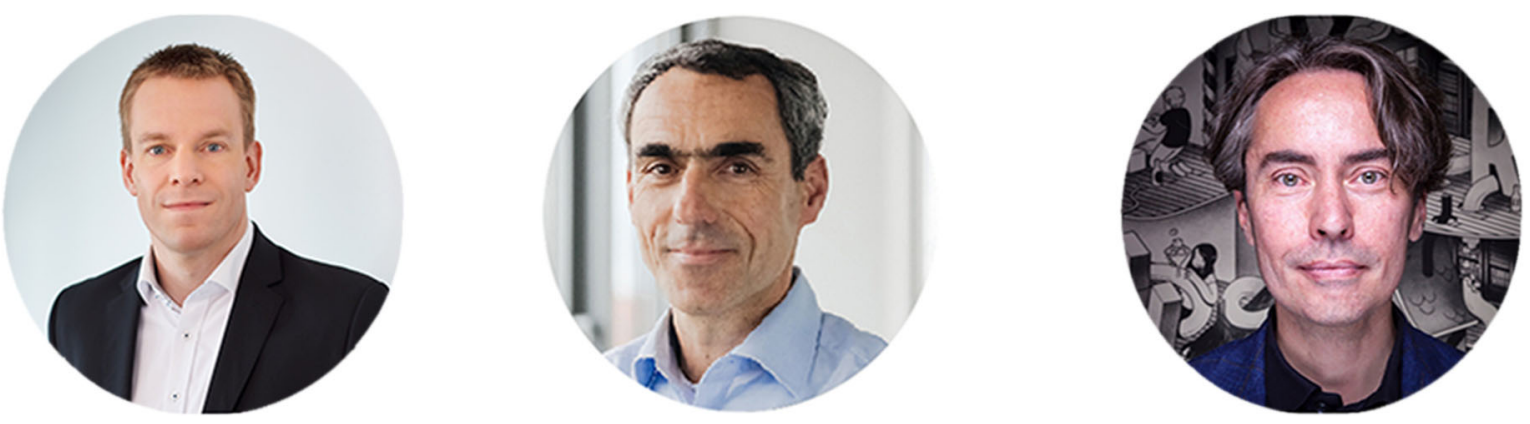

Rainer Alt

rainer.alt@uni-leipzig.de

Erik Wende

e.wende@ewerk.com

1 Information Systems Institute, Leipzig University, Grimmaische Str. 12, 04109 Leipzig, Germany

2 EWERK Digital GmbH, Brühl 24, 04109 Leipzig, Germany

\section{Energy exchanges: Enablers of global energy flows}

Energy or power exchanges are businesses that operate wholesale markets for buying and selling electricity (Andoni et al. 2019). They are neutral electronic marketplaces that provide efficient means for facilitating the trade of short- and longer-term energy products (e.g. electricity, 
gas), which include energy contracts as well as various derivatives, such as certificates, futures and options (Madlener and Kaufmann 2002). Energy exchanges emerged with the liberalization and the unbundling of the energy sector in the late 1990 s and early 2000 s in the European Union (EU). Production, transport, distribution and supply of energy were primarily organized in vertical silos and single entities with low efficiency as well as with little transparency. The EU's motivation was to split these functions in order to increase efficiency through market mechanisms and decentralization (Kranz et al. 2015). Energy exchanges offer (electronic) marketplaces that are overseen by national regulators and provide a transparent price signal through the aggregation of supply and demand. Many other international markets in the Americas and Asia followed the European energy market model and distinguish between two main market segments (for the energy value chain see Paukstadt and Becker 2019):

- The (financial) futures market trades energy for delivery in the mid- or long term, e.g., $100 \mathrm{MWh}$ of electricity for every hour of the next calendar year. This market focuses on hedging against price risks.

- The (physical) spot market trades energy for next or same-day delivery with the clear goal of physical delivery on the respective grid. This market mainly serves to hedge against volume risks.

The two market segments are not completely separate. For example, contracts on the futures market may be traded several times and the trading volumes on the futures market may exceed a country's annual consumption by several times. As soon as their delivery approaches, futures contracts are fulfilled on the spot market. Over time, the products traded on energy exchanges as well as the market participants have become more diverse. The latter range from large energy producers to transmission system operators, from regional and local energy suppliers to energy-intensive industries and from renewable energy producers to pure energy trading companies (Merz 2016). Various energy exchanges have emerged worldwide to enable an efficient coordination among these participants. Currently, exchanges exist on all continents and in analogy to the financial exchanges, most of these exchanges are electronic markets. Among the examples are ASX in Australia, EMC in Singapore, IEX and PXIL in India, JEPX in Japan, CME, ICE and Nasdaq in the US as well as EEX and Nord Pool in Europe (for an overview see Shah and Chatterjee 2020). Table 1 shows the trading volumes of EEX and ICE, which are the leading electronic marketplaces in their respective market segment and have also grown by acquiring smaller exchanges. Many of these marketplaces have a long tradition in electronic trading and have recognized the impact of blockchain technology on their processes and systems.
Although literature expects blockchain to have disruptive effects in the business of energy trading (e.g. Andoni et al. 2019; Merz 2016; Xu et al. 2019), many prototypes have not left this stage. This interview aims to shed light on the current status from the perspective of EEX.

\section{The interview}

\section{EEX company profile}

EEX is the leading energy exchange in Europe. It offers contracts on power, natural gas and emission allowances, as well as freight and agricultural products. EEX also provides registry services for white (or energy saving) certificates, capacity certificates and guarantees of origin on behalf of the French State, as well as auctions for guarantees of origin. EEX is part of EEX Group, which operates electronic market platforms for energy and commodity products across the globe and provides access to a network of 670 trading participants in 38 countries (2019). The Group's offering includes trading products for energy, environmental products, freight, metals and agricultural products, as well as the supporting clearing and registry services. EEX Group comprises the companies EEX, EEX Asia, EPEX SPOT, Power Exchange Central Europe (PXE) and Nodal Exchange, as well as the registry operator Grexel Systems and the clearinghouses European Commodity Clearing (ECC) and Nodal Clear. EEX Group is a member of Deutsche Börse Group and headquartered in Leipzig, Germany.

\section{The expansion of renewable energies throughout Europe is leading to a decentralization of the energy industry. Is this an advantage for blockchain technology?}

The energy market is not a uniform business and consists of various levels of trading. In the European energy sector, we distinguish three levels or market categories. On the first level, there is the Europe-wide, cross-border wholesale business. The second level comprises the distribution networks or groups of distribution networks, and the third level is the decentralized level of individual households. At all three levels, various technologies can be used. In the wholesale market, technologies are already well developed, and the blockchain, as such, does not offer substantial added value here. Instead, it may be regarded as another technological option, which more or less faces the same challenges as the established systems. An important aspect is speed: At the exchange, we have highly developed trading systems, which are also used in high-frequency trading and whose efficiency the blockchain does not get anywhere close to. The existing systems also comprise clearing solutions, which already guarantee a high degree of trust among the market participants. Even the idea of regional and local platforms is 
Table 1 Transnational energy exchange trading volumes worldwide 2019 (Sources: Annual reports of EEX and ICE)

\begin{tabular}{lll}
\hline & Electricity & Gas \\
\hline EEX & $6428 \mathrm{TWh}$ & $2546 \mathrm{TWh}$ \\
ICE & $550 \mathrm{TWh}$ & $9406 \mathrm{TWh}$ \\
\hline
\end{tabular}

not new and was not invented with the blockchain. However, these decentralized markets involve a number of challenges: A situation must be avoided in regional markets in which every region or, in extreme cases, every street uses its own technology and its own platform. Of course, the technological structure can develop in parallel with the economic structure, but there should still be a certain level of standardization in terms of technology. We also need the option of coupling the different levels to avoid inefficiencies in the market. For example, it would be important to sell surplus volumes from one region through a competitive organized market in other regions.

\section{Which role do you see for EEX in the decentralized markets?}

We believe that there remains a need for energy exchanges even in a completely decentralized market. We will further enhance the current wholesale market and are developing products for renewable energies. One example is the ENERA project carried out in the framework of the socalled "Energy Showcase," a program sponsored by the German Federal Ministry of Economic Affairs, which specifically addresses these questions in the $\mathrm{EWE}^{1}$ grid area (i.e., northern Germany). This project aims to integrate decentralized systems into the market within the EWE grid area, and the results have been very positive so far: The first trade was settled in February 2019, and the trading platform permitted very short-term and local trading - in addition to the existing intraday exchange market. This solution is not blockchain-based, although that was initially considered as an option. The project shows how standards can be established by involving various players and by having them jointly define the products. This is only one example of a possible role of the exchange that, in my opinion, is promising and will be important for the overall system to work effectively. In addition, new business models might evolve. For example, in 2018, we launched the platform enermarket to facilitate $\mathrm{B} 2 \mathrm{~B}$ trading between smaller companies. This enabled them to participate in the wholesale market, which had not been feasible prior to that due to their limited energy volumes.

\footnotetext{
${ }^{1}$ EWE NETZ GmbH is responsible for the network infrastructure for electricity, natural gas, telecommunications and drinking water in the German regions Ems/Weser/Elbe, East Brandenburg, northern West Pomerania and Rügen.
}

\section{Exchanges will also establish bridges between market categories?}

Yes, exactly. However, in this context, we are not primarily driven by technology because bringing together different market participants with a variety of trading interests is simply our core competence. It is part of our DNA as a market operator. Therefore, we strive to connect players from different categories or levels (i.e., regional and wholesale trading) and across different technologies. At present, the number of potential market players is also increasing and it is in this environment that we can significantly contribute.

\section{How important is transaction volume for new products?}

In smaller bilateral segments, we have started to establish a slightly different position than exchanges usually have in less dynamic commodity markets. In many markets, it is not unusual for standards to evolve in over-the-counter (OTC) markets with volumes increasingly concentrating on individual contracts, which are then transferred to the exchange. In the past, exchanges often were followers in the application of standards, but this is not our position in the European energy market. We aim to actively shape market development and have already shown that. For example, we offer dedicated products for renewable energies, including the very first products tailor-made for this segment: This wind power future was introduced as a standardized exchange-traded derivative to enable the dedicated hedging of the wind power generation risk. There is no frequent trading in these instruments, but we do not measure our success in volumes. We aim to actively develop new markets and show that the market provides innovative solutions. We are pursuing the same path with regard to the regionalization of the market.

\section{Blockchain technology has given rise to many technological frameworks, such as Ethereum or IOTA. Is there a framework that is particularly suited for exchanges or even energy trading?}

We have looked at many of these frameworks. In general, solutions that offer high performance correspond more closely to our requirements. However, even these fail to resolve the real-time and scalability requirements of a large electronic market. To offer a superior business model, such a solution would have to match the technical features of existing trading systems. One of the necessary conditions for a disruptive technology is that it offers an additional benefit. At the moment, we are observing many concurrent developments because decentralization coincides with digitalization, while new technologies, such as the blockchain, are evolving. Therefore, it is important to be involved at various points of these processes to ensure the 
harmonization and interconnection of all these individual new platforms.

\section{Are there any pilot projects in this field within the EEX group?}

EEX Group is participating, via EPEX SPOT, in a cooperation with our partner LO3 ENERGY. LO3 is an energy startup that first organized peer-to-peer energy trading within a microgrid using blockchain. Within this cooperation, we aim to connect such microgrids to the European wholesale market. To this end, we have signed memoranda of understanding with LO3, but the project is still in the design phase. We believe that blockchain can bring a benefit for energy optimization within a microgrid, and we are ready to introduce such initiatives to the EPEX SPOT markets.

\section{What were the main learnings from these projects?}

First of all, we have observed that all market participants dealing with blockchain technology are largely doing this with a view to simplifying back-office processes and lowering costs in the settlement of transactions. This would be in line with our interest in supporting market participants to simplify settlements at the exchange and the clearinghouse. However, the blockchain prototypes we know are inferior to the existing functions of exchanges and their clearing organizations. For example, instead of price negotiations within the blockchain, bilateral transactions were recorded in the blockchain, so the actual trading activity did not take place within the blockchain. Moreover, trust between the participants is not ensured through the blockchain as such. Although every transaction may be traced, the blockchain does not guarantee that one counterpart to a transaction receives the amount due in euros, dollars or any other currency from his counterpart, unless the transaction is settled in a cryptocurrency within the blockchain.

\section{Coming back to the role of exchanges as possible standard setters, what could this mean in the context of blockchain technology?}

Ultimately, standards facilitate many things for the end-consumer. We are working to simplify access to the large standardized wholesale market for small market participants. As a matter of fact, decentralized players typically choose to access exchanges through intermediaries in order to use economies of scale. We are working to reduce obstacles because we believe that, five years from now, a growing number of small participants will actively participate in the market. As a result, they are also given access to the standard, which, in turn, helps them in overcoming settlement inefficiencies.

\section{What were the most important obstacles observed in blockchain pilot projects?}

A key task that has not yet been fully resolved refers to the products to be traded in the blockchain. For example, one kilowatt hour may be generated from different primary energy sources and be traded for different prices. Existing projects diverged at this point. Furthermore, there is the question of who owns the data in the blockchain: Is it the local energy supplier or a community of participants? How are consumers in households or decentralized generation facilities connected to the blockchain? In addition, we need to resolve the question on the extent of automation of trading and, ultimately, how payments are settled in the real world - at least, unless payments are not made in the blockchain.

\section{What is the major contribution of blockchain technology regarding these challenges?}

If a transaction on the exchange is concluded - regardless of whether it is with a counterpart in a certain market area or in another market area leading to border-crossing trading - the trade is confirmed within minutes. The trade is then forwarded to the clearinghouse and the parties receive a confirmation that their trade will be fulfilled rapidly. This way, sellers know that the purchase price will be paid even if the fulfilment of the transaction is years in the future. This means that there are no inefficiencies in this process. On the contrary, a period of weeks in the settlement of transactions applies in bilateral trading (e.g., based on the negotiation of loan agreements and contract specifications, etc.). This is where the blockchain can contribute.

\section{How do you assess the technical characteristics of blockchain technology for energy trading?}

In the short-term power market, the availability of the technological systems is a challenge. This is where blockchain is certainly competitive because of its decentralized organization. However, as far as transaction speed is concerned, the centralized trading system is still superior to the blockchain prototypes available today. In intraday power trading, we already have algorithmic automated trading with latency periods in the millisecond range. No blockchain prototype available today can keep up with this. Despite the fact that further technological progress will happen, the disruptive effects will not be driven by technology but by business models at the end of the day. Here, blockchain solutions have to prove that they can offer a true added value over the existing trading systems. 


\section{Are there other potentials of blockchain technology in the exchange environment?}

We think blockchain technology is suitable in the entire field of registries for electronic certificates. In our opinion, there is high potential in particular in the field of guarantees of origin over the coming years. For example, we conducted the first successful auctions for guarantees of origin for the French government. We think there is the potential that smaller power plant operators might connect to those systems. Private homeowners with a photovoltaic plant on the roof may be issued guarantees of origin via their upstream energy suppliers and may resell these via a blockchain system. In contrast to this, buyers benefit because they know with certainty where the guarantee of origin comes from. This is a new market with new players, and this is where blockchain technology could use one of its characteristics - namely the cost-effective connection of a large number of trading participants. It will not require extensive computing power but, instead, the flexibility to define the individual products. We will observe such developments as well as the experiences in the area of LO3, which are still limited to energy trading rather than certificates.

\section{How important are smart contracts for energy trading?}

In my opinion, we need to strictly separate the subject of smart contracts from the automation of trading. For example, years ago, only hours of energy could be traded in intraday trading, but this has been expanded to time slices of fifteen minutes. These contracts are then, in turn, smartly coupled to 30-min contracts at market boundaries where the balancing period is $30 \mathrm{~min}$. This means that liquidity may be bundled across borders. Contracts linked via "if-then" conditions form another example. In this respect, the current market is already relatively smart. Some large energy suppliers that operate on the intraday market offer their customers even more fragmented products. These are then bundled by the energy supplier, who only balances the residual volumes on the intraday market. There are some applications where energy suppliers source energy from photovoltaic plants or wind energy plants, partly bundle this flexibility on the load side and then balance the remaining profile via the intraday market. In many cases, this is already done automatically by connecting the plants directly to the trading system via interfaces. Although this is already a typical application for a blockchain at the decentralized level, this problem has largely been resolved with the help of smart orders, a flexible product offering in trading and the automation of the trading interface.

\section{Does the blockchain offer any advantage to such scenarios?}

I actually only see an advantage for blockchain under two conditions: with individual access by the local end-consumer or when the energy sold or the guarantee of origin is important. Wherever consumers desire to actively participate in the market, blockchain technology certainly forms an interesting option. At present, however, consumers do not have such an interest because they value a finished solution for a given problem. Therefore, in our opinion, blockchain is not the technology of choice, and under these circumstances, there is little incentive to participate in the blockchain.

\section{What does the strong regulation of the energy market mean for blockchain technology?}

Today's energy markets are strongly regulated and subject to financial market regulation along with all the reporting obligations resulting from this. For example, since early 2018, all transactions and positions held by participants in a market need to be reported on a daily and weekly basis under the EU MIFID II $^{2}$ directive. We offer this to our customers centrally via the systems of the exchanges that have this data. In addition, reporting requirements may be submitted to the exchange for transactions concluded off the exchange because we are able to provide all data from one source. Today, we use our own management systems to this end, and new technologies might offer an efficiency potential here. However, they have not progressed sufficiently to replace existing systems. This applies in particular to performance: The number of transactions in the markets is so high that the time required to report an individual transaction is important. Otherwise, it will not be possible to submit the reports in due time at the end of the day before the market starts on the following day.

\section{Does this mean that regulation makes the wholesale market less attractive for blockchain technology?}

Basically, this is not a contradiction. Among other things, regulation of the energy market addresses a problem blockchain has been unable to resolve. Blockchain technology can securely trace who purchased which product, for example a given kilowatt hour or a certificate. However, it fails to resolve the issue of whether the product purchased in the blockchain corresponds to an equivalent value in the real world. This raises the question of trust between participants in

\footnotetext{
${ }^{2}$ MiFID II is the Markets in Financial Instruments Directive and is applicable across the European Union. This legislative framework aims at strengthening investor protection and improving the functioning of financial markets, making them more efficient, resilient and transparent.
} 
the blockchain and the real world. It is here where the production and consumption facilities are located and, ultimately, payments are still settled today. At least, for the financial part, there are possible blockchain solutions. However, complete trust in the blockchain requires all business relationships between contracting partners to be settled within this system. It is here where regulation comes in since trust in the physical world is of foremost importance in energy markets. Buyers or sellers must simply trust energy generators and consumers to behave as agreed in trading and not to fail, which would lead to an imbalance in the grid. As it stands today, blockchain cannot yet safeguard this.

\section{How close will energy exchanges move to the end consumers?}

This will certainly happen to the degree to which consumers assume the role of prosumers and actively participate in the market. The development is clearly going in this direction, though I do not expect that this makes every consumer a fullyfledged wholesale participant. The needs of end consumers and large, centralized businesses are simply too different. Nevertheless, this borderline will become increasingly vague. We are working to find ways that allow consumers to participate in the market if they wish. For all others, intermediary trading participants will provide the bridge even in the future.

Dear Tobias, thank you for the interview.

Funding information Open Access funding provided by Projekt DEAL.

Open Access This article is licensed under a Creative Commons Attribution 4.0 International License, which permits use, sharing, adaptation, distribution and reproduction in any medium or format, as long as you give appropriate credit to the original author(s) and the source, provide a link to the Creative Commons licence, and indicate if changes were made. The images or other third party material in this article are included in the article's Creative Commons licence, unless indicated otherwise in a credit line to the material. If material is not included in the article's Creative Commons licence and your intended use is not permitted by statutory regulation or exceeds the permitted use, you will need to obtain permission directly from the copyright holder. To view a copy of this licence, visit http://creativecommons.org/licenses/by/4.0/.

\section{References}

Andoni, M., Robu, V., Flynn, D., Abram, S., Geach, D., Jenkins, D., McCallum, P., \& Peacock, A. (2019). Blockchain technology in the energy sector: A systematic review of challenges and opportunities. Renewable and Sustainable Energy Reviews, 100, 143-174. https://doi.org/10.1016/j.rser.2018.10.014 .

Kranz, J., Kolbe, L. M., Koo, C., \& Boudreau, M. C. (2015). Smart energy: Where do we stand and where should we go? Electronic Markets, 25(1), 7-16. https://doi.org/10.1007/s12525-015-0180-3 .

Madlener, R., \& Kaufmann, M. (2002). Power exchange spot market trading in Europe: Theoretical considerations and empirical evidence. OSCOGEN (Optimisation of cogeneration systems in a competitive market environment)-project deliverable 5 (2002). http:// www.oscogen.ethz.ch/reports/oscogen_dp5 010702.pdf. Accessed 25 Mar 2020.

Merz, M. (2016), Potential of the Blockchain technology in energy trading. Blockchain Technology, DeGruyter. https://www.researchgate. net/publication/315102435_Potential_of the Blockchain Technology_in_Energy_Trading. Accessed 25 Mar 2020.

Paukstadt, U., \& Becker, J. (2019). Uncovering the business value of the internet of things in the energy domain - a review of smart energy business models. Electronic Markets. https://doi.org/10.1007/ s12525-019-00381-8.

Shah, D., \& Chatterjee, S. (2020). A comprehensive review on day-ahead electricity market and important features of world's major electric power exchanges. International Transactions on Electrical Energy Systems. https://doi.org/10.1002/2050-7038.12360.

Xu, Y., Ahokangas, P., Yrjölä, S., \& Koivumäki, T. (2019). The fifth archetype of electricity market: The blockchain marketplace. Wireless Networks. https://doi.org/10.1007/s11276-019-02065-9 .

Publisher's note Springer Nature remains neutral with regard to jurisdictional claims in published maps and institutional affiliations. 